Int. J. Dev. Biol. 53: 163-168 (2009)

doi: $10.1387 / \mathrm{ijdb} .072311 \mathrm{zf}$

\title{
Expression patterns of Src-family tyrosine kinases during Xenopus laevis development
}

\author{
ZOLTAN FERJENTSIK ${ }^{1,2}$, RADEK SINDELKA ${ }^{1}$, JIRI JONAK*,1,3 \\ ${ }^{1}$ Laboratory of Gene Expression and Laboratory of Bacteriology, Institute of Molecular Genetics, Academy of Sciences of the Czech \\ Republic v.v.i, Czech Republic, ${ }^{2}$ Division of Cell and Developmental Biology, University of Dundee, Dow Street, Dundee, UK and \\ IInstitute of Medical Biochemistry, First Medical Faculty, Charles University, Czech Republic
}

\begin{abstract}
Src family tyrosine kinases (SFKs) play important roles in cell morphology, differentiation, motility and proliferation. Elevated expression and/or specific activity of Src kinases are characteristic for several types of human cancer. However, little information is available about the role and spatio-temporal expression of SFKs in early embryonic development. In this study we characterized, in Xenopus laevis, the expression patterns of five SFK genes src, fyn, yes, lyn and laloo as well as of the csk gene, a negative regulator of SFKs, using RT-qPCR and in situ hybridisation. We found that transcripts of all SFKs and csk were already detectable in one-cell embryos and their levels similarly oscillated during subsequent development. First, after stage 8, the levels of SFK and csk mRNAs began to decrease, reached a minimum between stages 10 and 28 and increased again. In the later stages (33-45), the levels of fyn, yes and csk mRNAs returned to approximately maternal ones, whereas the src, laloo and lyn mRNA transcripts exceeded, up to about 3.5-6-fold, their maternal levels. In situ hybridisation analysis located the SFK and csk transcripts in the animal hemisphere of Xenopus embryos. Subsequent gastrula stages showed signals in ectodermal cells, mid-neurula stage embryos at neural folds, and the tailbud stages showed strong signals in the brain and neural tube. RT-qPCR concentration profiling along the animal-vegetal axis proved in blastula and gastrula the preferential localisation of yes, src, lyn and csk transcripts towards the animal pole in a gradient-like manner. In contrast, laloo and fyn displayed a vegetal pole preference.
\end{abstract}

KEY WORDS: Xenopus laevis, quantitative real-time PCR, in situ hybridisation, early development

Src and Src-family protein-tyrosine kinases (SFKs) are protooncogenes and represent one of the nine presently recognised classes of non-receptor tyrosine-kinases (Pellicena and Miller, 2002). As documented in a great many reports the members of the SFK family participate in a variety of signalling pathways that control cell behavior, including differentiation and transformation (for a review see e.g. Blume-Jensen and Hunter, 2001). On the other hand, the role of SFK members in developmental processes has been examined much less extensively. The experiments carried out on mice demonstrated that Src/Fyn and Src/Yesdouble knockouts die perinatally (Stein et al., 1994) and Src/Fyn/ Yes-triple knockouts at an early stage of embryonic development (Klinghoffer et al., 1999).

In frogs Xenopus laevis, Steele and co-workers reported that src, yes, and fyntranscripts were already present in the maternal RNA pool (Steele, 1985; Steele et al., 1989, 1990). In contrast to mice, studies on frogs allowed in vitro direct and continuous observation and examination of developing embryos from the time of fertilization. We found that overexpression of Src kinase over a certain threshold resulted either in defective gastrulation and death, or in the development of malformed embryos characterized by a depressed level of cadherin and $\alpha$-, $\beta$ - and $\gamma$-catenins in their tissues (Taka et al., 1998, Jonák, 2000, DvoYákova, 2000). Curiously, SFK downregulation had similar effects. Injection of antisense RNAs against Src, Fyn and Yes led to the failure of $X$. laevis blastopore and neural tube closure, to shortening of the anterior-posterior axis or other defects in embryogenesis (Denoyelle et al., 2001). This demonstrated that the level of Src must be strictly kept within certain boundaries; both too high and

Abbreviations used in this paper: SFK, Src family tyrosine kinase.

\footnotetext{
*Address correspondence to: Jiri Jonak. Institute of Molecular Genetics, v.v.i, Vídenská 1083, Prague 4, 14220, Czech Republic. Fax: +420 $22431-0955$. e-mail: jjon@img.cas.cz
} 
too low level of Src has deleterious effects on the development. Src does not seem to have a role in mesoderm differentiation (Denoyelle et al., 2001), but Fyn and Laloo could induce mesoderm formation in Xenopus animal caps assays (Weinstein et al., 2001). In situhybridisation analysis of Xenopus embryos demonstrated nervous system-specific expression of srcmRNA (Collett and Steele, 1992) and fyn mRNA (Saito et al., 2001), suggesting that $s r c$ and fyn may play a role in elaboration of the nervous system.

RT-PCR analysis of csk and laloo expression during early Xenopus development showed maternally present transcripts, a greatly diminished expression by mid-blastula stages and a rise in expression again in late neurula stages (Song et al., 2001).

The spatial and temporal changes in gene expression are a key mechanism in embryo development. However, as summarized above, such information about SFK members is only fragmentary. Therefore, in the current study, we have utilized a quantitative real-time PCR (RT-qPCR) protocol to examine and compare expression levels of five SFK genes src, fyn, yes, Iyn and laloo, and of $c s k$, the negative regulator of SFKs, during the period of early development of $X$. laevis. In addition, we have also detailed the spatio-temporal expression patterns of csk and all five SFK genes using the whole-mount in situhybridisation and determined intraembryonal distribution of their transcripts along the animalvegetal axis by RT-qPCR.

\section{Quantitative real-time PCR}

The temporal expression patterns of src, fyn, yes, lyn, lalooand cskmRNAs determined by RT-qPCR are shown in Fig. 1. Previously, we demonstrated that RT-qPCR normalisation of mRNA expression patterns to reference genes such as ODC, GADPH, EF- $1 \alpha, \mathrm{H} 4$ or L8, widely used in Xenopus RT-qPCR experiments, is not particularly suitable, because their levels vary during Xenopus development. We found that normalisation to total RNA is more appropriate (Sindelka et al., 2006). Therefore, the mRNA expression profiles of $s c c, f y n, y e s, l y n$, laloo and csk in stage series were normalised to total RNA of each embryonic stage and to stage one, and are presented in arbitrary units.

All five examined SFK mRNAs as well as the cskmRNA were already detectable in Xenopus one-cell embryos, indicating their maternal origin. This confirmed the results from Steele's laboratory (Steele, 1985; Steele et al., 1989, 1990) obtained for src, yes and fyn transcripts as well as for laloo and csk transcripts described in Song et al. (2001). Following fertilization, the levels of all examined mRNAs stayed stable up to about stage 8 (src, fyn, yes, lyn and csk) except for laloo, the level of which increased about 3 times to this stage. Then, the levels of all the transcripts began to decrease to a minimum. It was reached at stages 10.5 (src), 10-22 (fyn), 16-22 (yes, laloo, csk), or 10-16 (/yn). The levels of all transcripts then started to rise again obviously as a result of zygotic expression. The fyn, yes and csk mRNA levels roughly returned to maternal levels at around stage 41, 37 and 33, respectively, whereas src, laloo and Iyn mRNAs reached, in more than one of the later stages (33-45), levels about 3.5, 5 and 6-fold higher, respectively, than was their level in the fertilized one-cell embryos. The earliest onset of zygotic expression was detected for src mRNA, confirming the results of Collett and Steele (1992). The laloo temporal expression profile presented here complements the partial laloo expression data previously published by Weinstein et al. (1998) and also correlates very well with the RT-PCR expression analysis described in Song et al. (2001).

In order to quantitatively compare the expression efficiency of individual SFK and csk genes, we normalised their expression levels to that of Iyn mRNA (Fig. 2). While the separate expression patterns of the examined genes (Fig. 1) particularly highlight similarity in their expression profiles in the course of early development, the Iyn mRNA normalised patterns mainly visualise quantitative differences among individual SFK in the expression of their genes. The Fig. 2 shows that the levels of fynand laloomRNAs
Fig. 1. The mRNA expression profiles of Xenopus laevis src, fyn, yes, lyn, laloo and csk genes, normalised to total RNA and stage one and expressed in arbitrary units. The numbers on the vertical axis represent the ratio between the average amount of copies of a mRNA at a particular developmental stage and stage one normalised to the same amount of input RNA (means $\pm S D, n=6$ replicates). The numbers on the horizontal axis represent the Xenopus developmental stages determined according to Nieuwkoop and Faber (1967). 
Fig. 2. The mRNA expression profiles of Src family tyrosine kinases (SFKs) and csk. mRNA expression profiles are normalised to total RNA and stage one of lyn mRNA and expressed in arbitrary units. The numbers on the vertical axis represent the ratio between the average amount of copies of mRNA at a particular developmental stage and stage one normalised to lyn mRNA copy amount. The numbers on the horizontal axis represent the Xenopus developmental stages determined according to Nieuwkoop and Faber (1967).

are kept about 10 times lower throughout early development than are the levels of yes, lyn or src. Interestingly, the level of csk mRNA is maintained higher or approximately comparable with the highest levels of other examined SFK throughout all developmental stages (Fig. 2). This should not be surprising as Csk regulates activity of all SFK members. Indeed, its concentration profile follows most closely that of the most strongly expressed SFK member, the yes mRNA.

\section{Whole-mount in situ hybridisation}

To analyse the spatio-temporal expression patterns of SFKs and csk, we performed the whole-mount in situ hybridisation on Xenopus laevis embryos using digoxigenin-labeled antisense RNA probes. The sense RNA probes were used as negative controls and they did not show any signals. myoD digoxigenin-

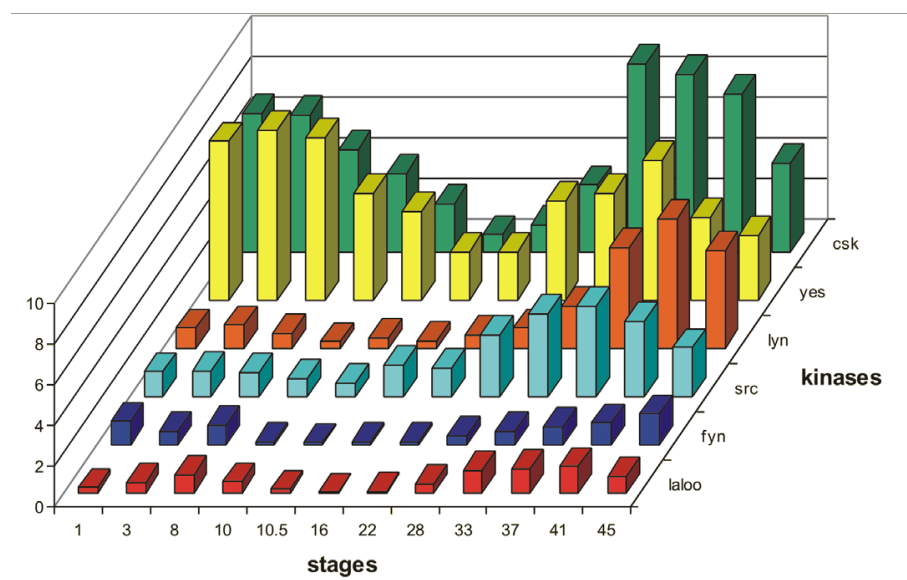

labeled antisense RNA probe was used as a positive control.

Expression of SFKs and csk was analysed from the one-cell stage to the tadpole stage 43 (Fig. 3), similarly as in the RT-qPCR experiments. In early cleavage stage embryos, SFKs and csk transcripts were detectable in the animal hemispheres but they were absent from the vegetal hemisphere (Fig. 3 A). At gastrula stages, the transcripts were detected only in the ectoderm layer (Fig. 3 B). In mid-neurula stage embryos, expression of SFKs and

A

src

$f y n$

yes

lyn

laloo

csk
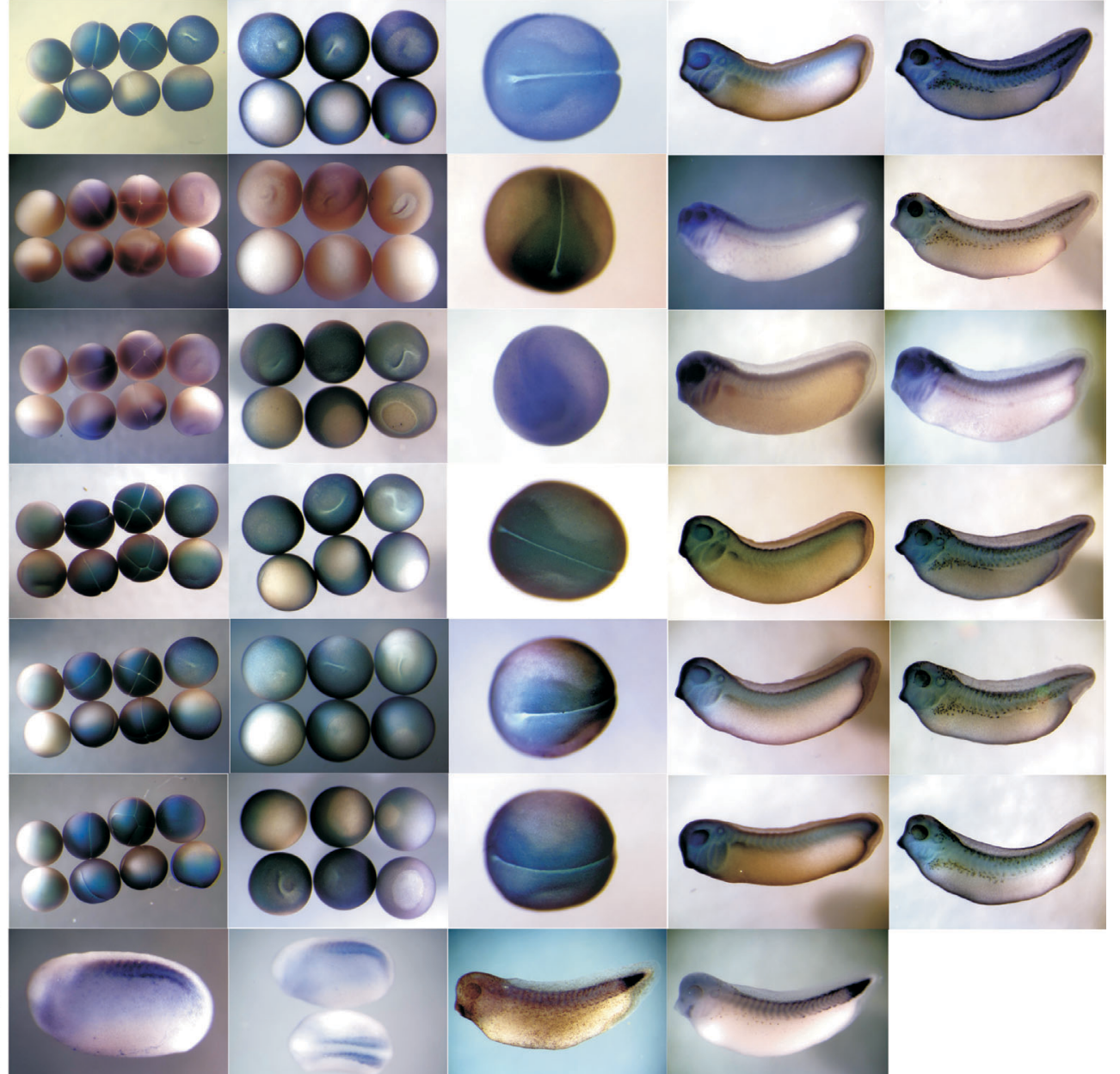


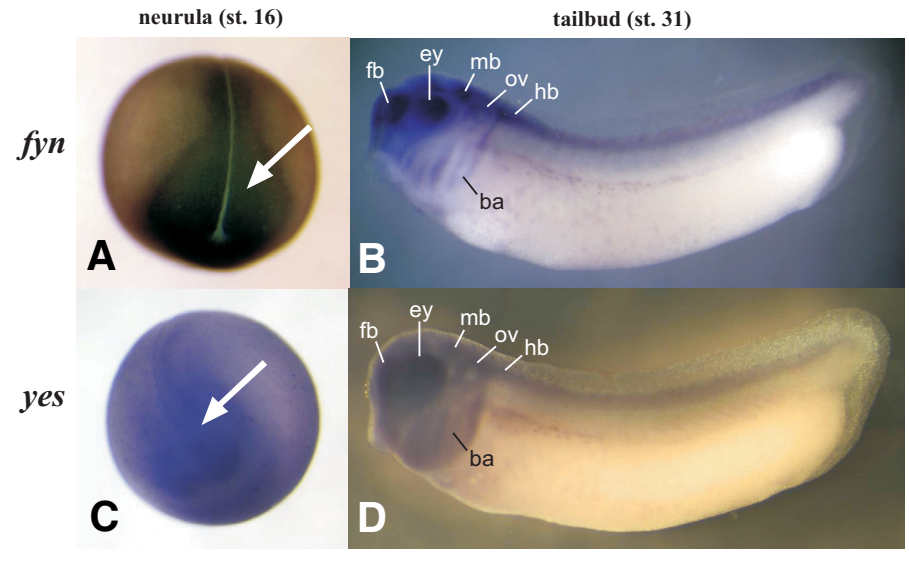

csk was detected at neural folds (Fig. $3 \mathrm{C}$ ).

At stages 28 and 31 (Fig. $3 \mathrm{D}, \mathrm{E}$ ), strong signals were found in the brain region of the neural tube and the expression of SFKs and csk also appeared in the eyes, branchial arches and otic vesicles. Fyn (Fig. 4 B) and yes (Fig. 4 D) expression at tailbud stage persisted in the forebrain, midbrain, hindbrain, neural tube, eyes, otic vesicles and branchial arches. The expression of SFKs and cskbecame ubiquitous from tadpole stage 41 (not shown).

We conclude that SFKs as well as their negative regulator cskare in Xenopusexpressed maternally, their levels oscillate; decline around stage 10.5 and resume again in later developmental stages. Quantitatively, the levels of yes, lyn and src mRNAs detected in early embryos are several times higher than those of fynand laloo and comparable with the level of csk mRNA. Expression of SFKs and csk is transiently nervous system-specific as documented in the whole-mount in situ hybridisation experiments.

\section{Detailed RT-qPCR analysis of blastula and gastrula stage}

To verify, by RT-qPCR analysis, the early ectodermal pattern of some SFKs and cskexpression described above, we determined concentration profiles of transcripts of all kinases along the animalvegetal $(A / V)$ axis in blastula and gastrula stage embryos. Blastula embryos (stage 8.5) were dissected into three portions (animal pole, marginal zone, and vegetal pole), gastrula embryos (stage 11) into four portions (animal pole, dorsal and ventral marginal zone and

Fig. 5. "Intraembryonal" expression analysis of Xenopus Src-family tyrosine kinases (SFK) and csk mRNAs at blastula and gastrula stages by RT-qPCR. Blastula (8.5) stage (A) and gastrula (11) stage (B) embryos were dissected into three (animal, marginal, vegetal) and four (animal, dorsal-marginal, ventral-marginal, vegetal), respectively, sections along the animal-vegetal axis as indicated and analysed as described in Materials and Methods.
Fig. 4. Detailed expression patterns of Xenopus fyn and yes genes. The fyn gene expression patterns (A,B). Anterior view (A) of Xenopus embryo at neurula stage. The arrow shows the expression of the fyn gene in neural folds. Lateral view (B) of a tailbud (stage 31) embryo. Fyn expression persists in the developing brain, neural tube, eye, branchial arches and otic vesicle. The yes gene expression pattern (C,D). Anterior view (C) of Xenopus embryo at neurula stage. The arrow shows the expression ofyes gene in neural folds. Lateral view (D) of embryo at stage 31. The arrows show the major expression of yes gene in the developing brain, neural tube, eye, branchial arches and otic vesicle. hb; hindbrain, mb; midbrain, fb; forebrain, ba; branchial arches, ey; eye, ov; otic vesicle.

vegetal pole; see scheme in Fig. 5) and the portions were subjected to RT-qPCR analysis. The amount of transcripts in each section was expressed in per cent of the overall content of individual transcripts present in the whole embryo.

This RT-qPCR "intraembryonal" analysis detected majority of yes, src, lyn and csk transcripts in the animal pole portion, less in the marginal zone portion and still less in the vegetal pole portion of the embryos. Yes, src, lynand csktranscripts formed concentration gradients along the embryonic $X$. laevis animalvegetal axis (Fig. 5). Approximately $50 \%$ of transcripts of these kinases were present in the animal pole portion, approximately $30-40 \%$ in the marginal zone portion and less than $20 \%$ of transcripts were present in vegetal pole portion of blastula stage embryos (Fig. 5 A). Very similar concentration ratios among the animal, marginal and vegetal transcripts of yes, src, lyn and cskwere also detected in gastrula stage embryos (Fig. 5 B). No significant differences in expression levels of these kinases in dorsal and ventral marginal zones were detected. Altogether, these findings are in good agreement with the data obtained by in situ hybridisation (Fig. 3 A, B) and yes, src, lyn
A

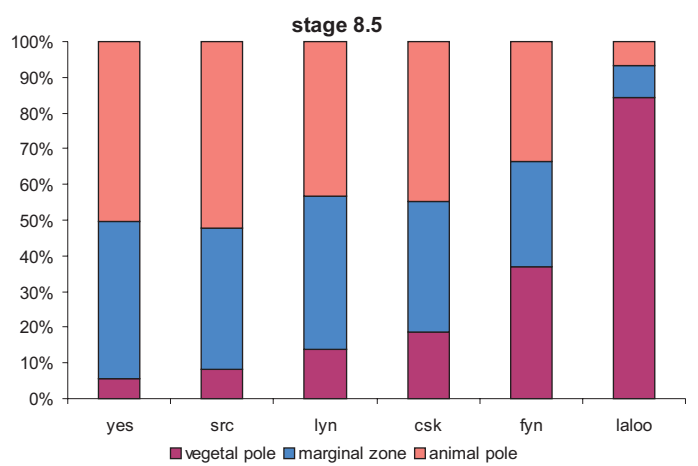

B

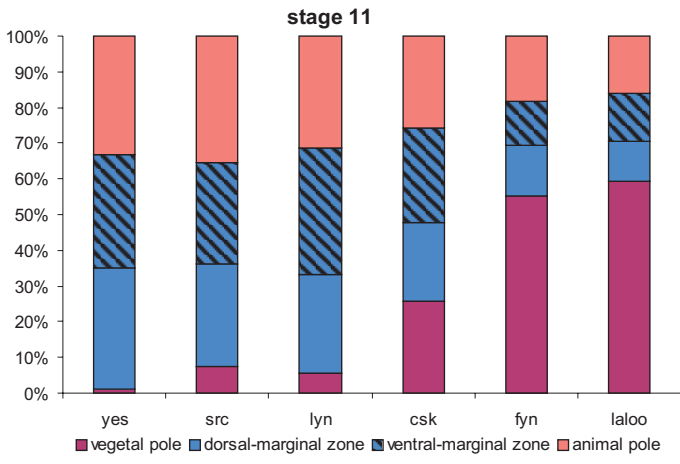

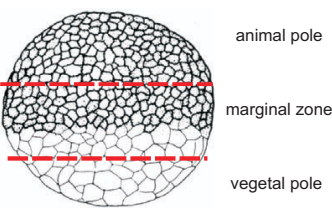

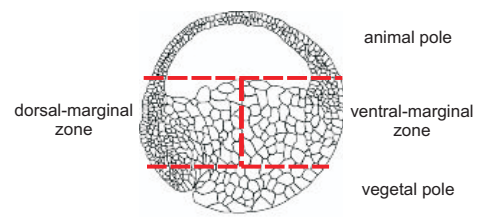


and csk could be considered as "animal genes".

On the other hand, expression patterns of fyn and laloowere found to be different. The amount of fyntranscripts was distributed almost identically among all three $A / V$ sections of blastula stage embryos (Fig $5 \mathrm{~A}$ ), and at gastrula stage it increased towards the vegetal pole (Fig. 5 B). The laloomRNA expression pattern turned out to be quite opposite to that of yes, src, lynand cskmRNAs. More than $80 \%$ of laloo transcripts at the blastula stage and almost $60 \%$ at the gastrula stage were found to be located in the vegetal pole portion and could be considered as a "vegetal gene". Dorsal and ventral marginal zones of gastrula did not differ in expression of either fyn or laloo (5 B).

The expression profile of lalootranscripts determined by RTqPCR was not consistent with the in situ hybridisation results (Fig. 3 A, B). Possible reason could be a weaker penetration of RNA probes to cells of vegetal pole of Xenopusembryos as well as a lower concentration of both fyn and laloo transcripts in embryos in comparison to all other kinases examined here (Fig. 2). We believe that RT-qPCR can measure intraembryonal mRNA gradients with greater resolution and sensitivity than traditional in situ hybridisation. Compare also with RT-qPCR "tomography" carried out on X. leavis oocytes (Sindelka et al., 2008).

\section{Materials and Methods}

\section{Embryos and explants}

Xenopus laevis embryos were obtained by in vitro fertilization and staged according to the Nieuwkoop and Faber tables (Nieuwkoop and Faber, 1967). Embryos were dejellied in $2 \%$ cysteine (Sigma) $(\mathrm{pH} 8)$ and then cultured in 0.1xNAM (Slack and Forman, 1980).

To analyse the distribution of mRNA transcripts along the animalvegetal axis in blastula (8.5) and gastrula (11) stage Xenopus embryos they were manually dissected into three (animal, marginal, vegetal) and four, respectively, portions (see Fig. 5 for details) and subjected to real-time RT-qPCR expression analysis of SFKs and csk. The mRNA expression levels were normalised to total RNA and gapdh expression level.

\section{RNA probes}

Digoxygenin sense and antisense transcripts were synthesized using SP6/T7 RNA labelling kit (Roche) following the manufacturer's instructions.

Xenopus src, fyn, yes, lyn, laloo, cskcoding sequences were cloned into the pCS2- vector (kind gift of D. Turner) after PCR amplification using following primer pairs:

src sense, 5'-ccgctcgagatgggtgccactaaaagtaag-3' antisense, 5'-gctctagattaaaggttgtccccaggc-3'

fyn sense, 5'-ggaattccatgggctgtgtgcaatgcaag-3' antisense, 5'-ccgctcgagttacaggttgtctccaggctg-3'

yes sense, 5'-cgggatcctcatgggctgtataaaaagtaagg-3' antisense, 5'-ggaattccttatagattgtccccaggctggt-3'

Iyn sense, 5'-cgggatcctcatgggatgtataaaatcaaaaac-3' antisense, 5'-ggaattccctaaggctgttgttgatattg-3'

laloo sense, 5'-ggaattccatgggctgcatcaagtcaaag-3' antisense, 5'-ccgctcgagttaaggttgtgcctggtactg-3'

csk sense, 5'-ccgctcgagccatgtcggtggtacaggccc-3' antisense, 5'-gctctagatcagtgatacagttccttggc-3'.

Primers were designed using the published sequences for src $\mathrm{BC} 110764$, fyn X52188, yes X14377, Iyn AB003358, laloo AF081803 and csk AF052430.

For antisense RNA, the pCS2- vectors were linearized with BamHI (fyn, yes, lyn, laloo), HindlII (src) or Apal (csk). For sense RNA (negative control experiments), the pCS2- vectors were linearized with Notl. Both antisense- and sense-digoxigenin-labeled RNA probes were obtained using T7 or SP6 RNA polymerase (Roche). RNA probes were purified with ProbeQuant G-50 Micro Columns (Amersham) and checked by agarose gel electrophoresis. Synthesized control sense probes gave no staining after whole-mount in situhybridisation (results not shown).

\section{Whole-mount in situ hybridisation and sectioning}

Whole-mount in situ hybridisation was performed according to the standard protocol (Harland, 1991). The antisense src, fyn, yes, Iyn, laloo, and cskprobes were designed to hybridise specifically with their unique $\mathrm{N}$-terminal region.

\section{RNA isolation and cDNA preparation}

RNA was isolated from Xenopus tissue using the Trizol (Invitrogen) or TriReagent (Sigma) method of extraction. A cDNA pool was generated from total cellular RNA by using random oligonucleotides and MMLV reverse transcriptase as previously described (Sindelka et al., 2006).

\section{Quantitative real-time $R T-q P C R$}

The reaction was accomplished in a total volume of $25 \mu \mathrm{l}$. The reaction mixture contained $2 \mu \mathrm{l}$ of the cDNA template, $0.2 \mathrm{mM}$ dNTPs, $240 \mathrm{nM}$ forward and reverse primers, $1 \cup$ Taq polymerase (Promega), $2.5 \mu \mathrm{l}$ of supplied $10 \mathrm{x}$ buffer, $2 \mathrm{mM} \mathrm{MgCl}, 2.5 \mu \mathrm{l}$ of 10,000 -fold diluted SYBRGreen solution (Molecular Probes) and $0.25 \mu \mathrm{l}$ of $50 \mathrm{nM}$ Fluorescein solution (Bio-Rad). The reactions were measured in iCycler (BioRad) with cycling conditions: $95^{\circ} \mathrm{C}$ for $5 \mathrm{~min}, 40$ cycles at $95^{\circ} \mathrm{C}$ for 15 $\mathrm{sec}$ and $60^{\circ} \mathrm{C}$ for $60 \mathrm{sec}$. Serially diluted PCR fragments (standards), identical with those amplified in the real-time PCR experiment, were prepared to obtain calibration curves. Reaction efficiencies determined from calibration curves for each set of primers were between 85 and $100 \%$. The Cts (threshold cycles) of the samples and standards were analysed with Microsoft Excel program and the number of amplified cDNA copies as PCR products from particular stages of development were determined from calibration curves. The average deviation between Cts in parallel experiments did not exceed about $5 \%$ for all tested genes and stages. The expression profiles were derived from three independent $X$. laevis serial experiments. Specificity of every amplification reaction was verified by melting curve analysis and gel electrophoresis.

Primers used for real-time PCR were designed by using the Beacon Designer 2.00 program (Premier Biosoft International). Primers used are as follows:

src sense, 5'-gcgactgattgaggacaatgagta-3' antisense, 5'-aggagaattccaaaagaccagaca-3'

fyn sense, 5'-gccaggcaccatgtctccag-3' antisense, 5'-ctcctcagacaccacagcgtag-3'

yes sense, 5'-caccaacaccagtcccttaccc-3' antisense, 5'-atcttgcttcccaccagtcacc-3'

Iyn sense, 5'-atccagcttctcgtacaccaag-3' antisense, 5'-tccaccattctccatgctcttc-3'

laloo sense, 5'-tctaagcaccccagagagga-3' antisense, 5'-ccgctcgagctttagcaggagatggtccc-3'

csk sense, 5'-ggcaagctgagcattgacgaag-3' antisense, 5'-gcggctactgttccctccatc- 3 '

gapdh sense, 5'-gccgtgtatgtggtggaatct-3' antisense, 5'-aagttgtcgttgatgacctttgc-3'.

\section{Acknowledgements}

We thank Dr Gufa Lin for his kind assistance during in situ hybridisation experiments. This work was supported by grant 301/02/ 0408 from the Grant Agency of the Czech Republic (to J.J.) and by project AVOZ 50520514 awarded by the Academy of Sciences of the 


\section{Czech Republic.}

The in situ hybridisation experiments were performed by Z.F. in the laboratory of Professor Jonathan Slack at the University of Bath, supported by BSDB and EACR short-time fellowships. We would like to thank all members of his laboratory.

\section{References}

BLUME-JENSEN, P., HUNTER, T. (2001). Oncogenic kinase signaling. Nature 411: 355-365.

COLLETT, J.W., STEELE, R.E. (1992). Identification and developmental expression of Src+ mRNAs in Xenopus laevis. Dev. Biol. 152: 194-198.

DENOYELLE, M., VALLES, A.M., LENTZ, D., THIERY, J.P., BOYER, B. (2001). Mesoderm-independent regulation of gastrulation movements by the src tyrosine kinase in Xenopus embryo. Differentiation 69: 38-48.

DVORAKOVA, K., HABROVA, V., TAKAC, M., JONAK, J. (2000). Depression in the level of cadherin and alpha-, beta-, gamma-catenins in transgenic Xenopus laevis highly expressing c-Src. Folia Biol. (Praha) 46: 3-9.

HARLAND, R.M. (1991). In situhybridization: an improved whole-mount method for Xenopus embryos. Methods Cell Biol. 36: 685-695.

JONAK, J. (2000). Sperm-mediated preparation of transgenic Xenopus laevis and transmission of transgenic DNA to the next generation. Mol. Reprod. Dev. 56: 298-300.

KLINGHOFFER, R.A., SACHSENMAIER, C., COOPER, J.A., SORIANO, P. (1999). Src family kinases are required for integrin but not PDGFR signal transduction. EMBO J. 18: 2459-2471.

NIEUWKOOP, P.D. and FABER, J. (1967). Normal Table of Xenopus laevis (Daudin). Amsterdam: North-Holland.

PELLICENA, P., MILLER, W.T. (2002). Coupling kinase activation to substrate recognition in SRC-family tyrosine kinases. Front. Biosci. 7: d256-267.

SAITO, R., FUJITA, N., NAGATA, S. (2001). Overexpression of Fyn tyrosine kinase causes abnormal development of primary sensory neurons in Xenopus laevis embryos. Dev. Growth Differ. 43: 229-238.

SINDELKA, R., FERJENTSIK, Z., JONÁK, J. (2006). Developmental expression profiles of Xenopus laevis reference genes. Dev. Dyn. 235: 754-758.

SINDELKA, R., JONÁK, J., HANDS, R. BUSTIN, S. and KUBISTA, M. (2006). Intracellular expression profiles measured by real-time PCR tomography in the Xenopus laevis oocyte. Nucleic Acids Res. 36: 387-392.

SLACK, J.M., FORMAN, D. (1980). An interaction between dorsal and ventral regions of the marginal zone in early amphibian embryos. J. Embryol. Exp. Morphol. 56: 283-299.

SONG, Y., COHLER, A.N., WEINSTEIN, D.C. (2001). Regulation of Laloo by the Xenopus $\mathrm{C}$-terminal Src kinase (Xcsk) during early vertebrate development. Oncogene 20: 5210-5214.

STEELE, R.E. (1985). Two divergent cellular src genes are expressed in Xenopus laevis. Nucleic Acids Res. 13: 1747-1761.

STEELE, R.E., DENG, J.C., GHOSN, C.R., FERO, J.B. (1990). Structure and expression of fyn genes in Xenopus laevis. Oncogene 5: 369-376.

STEELE, R.E., IRWIN, M.Y., KNUDSEN, C.L., COLLETT, J.W., FERO, J.B. (1989). The yes proto-oncogene is present in amphibians and contributes to the maternal RNA pool in the oocyte. Oncogene Res. 4: 223-233.

STEIN, P.L., VOGEL, H., SORIANO, P. (1994). Combined deficiencies of Src, Fyn, and Yes tyrosine kinases in mutant mice. Genes Dev. 8: 1999-2007.

Takac, M., HABROVA, V., MACHA, J., CESKOVA, N., JONAK, J. (1998). Development of transgenic Xenopus laevis with a high C-src gene expression. Mol. Reprod. Dev. 50: 410-419.

WEINSTEIN, D.C., HEMMATI-BRIVANLOU, A.A. (2001). Src family kinase function during early Xenopus development. Dev. Dyn. 220: 163-168.

WEINSTEIN, D.C., MARDEN, J., CARNEVALI, F., HEMMATI-BRIVANLOU, A (1998). FGF-mediated mesoderm induction involves the Src-family kinase Laloo. Nature 394: 904-8. Erratum in: Nature (1998) 395: 921.

\section{Further Related Reading, published previously in the Int. J. Dev. Biol.}

See our recent Special Issue Fertilization, in honor of David L. Garbers and edited by Paul M. Wassarman and Victor D. Vacquier at: http://www.ijdb.ehu.es/web/contents.php?vol=52\&issue=5-6

See our recent Special Issue Ear Development edited by Fernando Giraldez and Bernd Fritzsch at: http://www.ijdb.ehu.es/web/contents.php?vol=51\&issue=6-7

Systematic screening for genes specifically expressed in the anterior neuroectoderm during early Xenopus development Noriyuki Takahashi, Naoko Tochimoto, Shin-Ya Ohmori, Hiroshi Mamada, Mari Itoh, Masako Inamori, Jun Shinga, Shin-Ichi Osada and Masanori Taira Int. J. Dev. Biol. (2005) 49: 939-951

Expression of the DTK receptor tyrosine kinase during zebrafish development. $M$ Jansa Perez, J A Walshe, K E Crosier and P S Crosier Int. J. Dev. Biol. (1996) 40: S101-S102

Involvement of non-receptor protein tyrosine kinases inexpression of differentiated phenotype by cells of retinal origin.

A Moszczynska and M Opas

Int. J. Dev. Biol. (1994) 38: 1-12

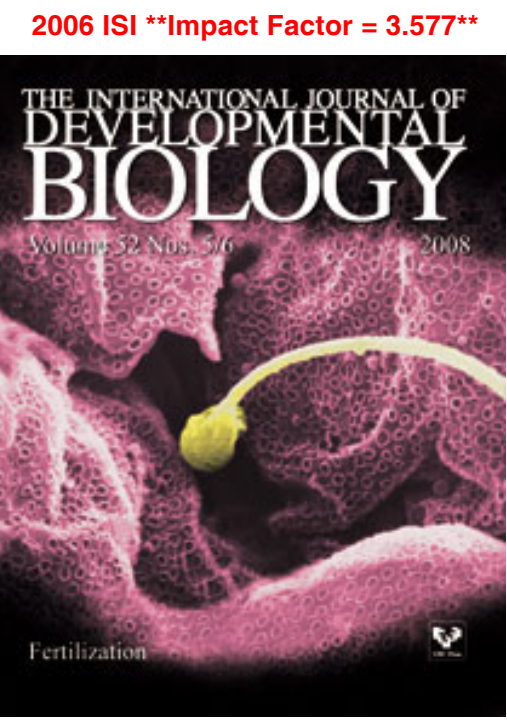

